NBER WORKING PAPER SERIES

"FIFTY-FOUR FORTY OR FIGHT!"

Herschel I. Grossman

Working Paper 9635

http://www.nber.org/papers/w9635

\author{
NATIONAL BUREAU OF ECONOMIC RESEARCH \\ 1050 Massachusetts Avenue \\ Cambridge, MA 02138 \\ April 2003
}

I have received helpful comments from Michelle Garfinkel, Dmitriy Gershenson, Francisco González, Simon Grant, Luis Locay, Donald Paterson, and Enrico Spolaore and from other participants in seminars at Texas A\&M University, at Rice University/University of Houston, at the International Center for Economic Research/ University of Turin, at the University of Bologna, and at the University of British Columbia. I thank Harl Ryder for technical assistance. The views expressed herein are those of the authors and not necessarily those of the National Bureau of Economic Research.

(C2003 by Herschel I. Grossman. All rights reserved. Short sections of text not to exceed two paragraphs, may be quoted without explicit permission provided that full credit including Cnotice, is given to the source. 
"Fifty-four Forty or Fight!"

Herschel I. Grossman

NBER Working Paper No. 9635

April 2003

JEL No. D74

\section{$\underline{\text { ABSTRACT }}$}

This paper develops an explanation for historical differences in the ways in which territorial disputes between sovereign states have been resolved. The main innovation in the analysis is to allow for three possible equilibria:

-Aan unfortified border;

-Aa fortified but peaceful border; and

-Aarmed conflict.

The analysis shows that the possibility of a credible agreement to divide a contested territory and to leave the resulting border unfortified depends on the effectiveness of spending on arms by one state relative to another and on the importance that states attach to the potential costs of future armed conflicts. The analysis also shows that, if all relevant parameters are common knowledge, then, even if an agreement to have an unfortified border would not be credible, states can resolve a territorial dispute peacefully by dividing the contested territory and fortifying the border. Finally, the paper points out that unverifiable innovations, especially innovations in military technology, can cause a peaceful settlement to break down, resulting in an armed conflict that in turn can provide the basis for a new peaceful settlement.

Herschel I. Grossman

Department of Economics

Brown University

Providence, RI 02912

and NBER

herschel_grossman@brown.edu 
The Democratic candidate, James Polk, won the American presidential election of 1844 on a platform that asserted the American claim to the entire Oregon territory, including the part that later became the Canadian province of British Columbia. The political slogan "Fifty-four Forty or Fight!", a reference to 54 degrees 40 minutes north latitude, dramatized this claim. ${ }^{1}$

But, the outcome of this territorial dispute was neither fifty-four forty nor fight. In the Oregon Treaty of 1846 the United States and Great Britain peacefully resolved their differences by dividing the Oregon territory between the United States and Canada.

While the United States and Great Britain were negotiating this peaceful settlement, they also were preparing for armed conflict. In the months preceeding the signing of the Oregon Treaty the British fortified Vancouver Island and the British Pacific Squadron patrolled the Oregon coast, while the United States government sent troops to protect American settlers on their way to Oregon. More importantly, the United States had reason to fear that in an armed conflict over the Oregon territory the British Navy would blockade and bombard American cities on the Atlantic coast, whereas the British increased their fortifications around the Great Lakes for fear that the Americans would press their claim to the Oregon territory by invading Ontario and the St. Lawrence Valley.

Today a territorial dispute between the United States and Canada, much less an armed conflict over the border between the United States and Canada, is unimaginable. In the decades following the Oregon Treaty the United States and Great Britain peacefully resolved territorial disputes that arose over the San Juan Islands, rights to hunt fur seals, and the boundary of Alaska. These agreements completed the demarcation of the current borders between the United States and Canada, which have now been both undisputed and unfortified for many years.

\footnotetext{
${ }^{1}$ The origin of the slogan is obscure. Both Edwin Miles (1957) and Hans Sperber (1957) conclude that, contrary to some accounts, it was not used during the election campaign of 1844 , but originated during the congressional debates that followed the election.
} 
In sharp contrast to the peaceful resolution of the dispute over the Oregon territory, in the same year, 1846, a territorial dispute between the United States and Mexico led to armed conflict, with disastrous consequences for Mexico. As the result of the Mexican-American War the United States annexed previously Mexican territories that now comprise Arizona, California, Nevada, New Mexico, Utah, and parts of Colorado and Texas. ${ }^{2}$

As a schoolboy I learned with pride that the United States and Canada enjoyed the world's longest unfortified border between sovereign states. In addition, my elders led me to believe that this happy state of affairs resulted from the moral superiority of Americans and Canadians, especially in contrast to Mexicans and also to Europeans, who, being greedy and quarrelsome, fortified their borders and, even worse, regularly engaged in wasteful and destructive territorial conflicts, the Second World War that had just ended being the latest example.

This paper develops a analysis that yields a less invidious explanation for historical differences in the ways in which territorial disputes between sovereign states have been resolved. This analysis is broadly relevant and applies to a wide variety of situations.

- The value of controlling a contested territory can comprise either economic factors, such as the revenue from exploitation of the territory's natural resources, as in the case of Oregon, or noneconomic considerations, such as geopolitical advantages that control of the territory confers, as in the case of Gibraltar.

- A contested territory can abut the uncontested domains of the parties to the dispute, as in the case of Oregon, Alsace, or Kashmir, or it can be separated by either land or sea from the uncontested domains of one of both of the parties, as in the cases of European states contesting control over colonies on other continents.

\footnotetext{
${ }^{2}$ David Pletcher (1973) provides an extensive account of political, diplomatic, and military developments in the simultaneous territorial disputes between the United States and Great Britain and between the United States and Mexico.
} 
- Control of a contested territory can involve explicit annexation and/or direct rule, as in all of the examples already mentioned, or it can involve the creation of client states and/or spheres of influence, as in the case of the Cold War between the United States and the Soviet Union.

- An armed conflict over control of a contested territory might or might not be confined to the contested territory itself. For example, the armed conflict between Argentina and Great Britain over the Malvinas/Falkland Islands took place entirely on the Islands and the nearby seas. In contrast, in the Mexican-American War, although the United States had no serious intention of annexing all of Mexico, the American military strategy included an invasion of the Mexican heartland.

- Although fortifications, which play a critical role in the analysis, can be, like the Maginot Line and the Seigfried Line, literally on the border between the parties to the dispute, fortifications more generally include any preparations for armed conflict over a contested territory, such as the possible positioning of British warships off the Atlantic coast of the United States in anticipation of armed conflict over Oregon.

The main innovation in the analysis is to allow for three possible equilibria:

- an unfortified border, like the present borders between the United States and Canada;

- a fortified but peaceful border, like the border between the United States and Canada in 1846; and

- armed conflict, like the Mexican-American War.

The analysis of these equilibria is based on three complementary ideas. The first idea,which derives from the standard theory of repeated interactions between adversaries, is that a credible agreement to settle a territorial dispute peacefully involves a division of the contested territory. The second idea, which derives from the work of Michelle Garfinkel (1990) on 
the strategic role of arms in international conflict, is that a credible agreement to settle a territorial dispute peacefully can require a fortified border. ${ }^{3}$

The present paper integrates these two ideas. The analysis shows that the possibility of credible agreement to divide a contested territory and to leave the resulting border unfortified depends on the effectiveness of spending on arms by one state relative to another and on the importance that states attach to the potential costs of future armed conflicts. The analysis also shows that, if all relevant parameters are common knowledge, then, even if an agreement to have an unfortified border would not be credible, states can resolve a territorial dispute peacefully by dividing the contested territory and fortifying the border. This result formalizes two well-known prescriptions: Qui desiderat pacem, preparet bellum. Also, "good fences make good neighbors." In addition we see that the same factors that determine whether an unfortified border is possible also determine how a credible peaceful settlement would divide control of a contested territory and what amount of fortifications a peaceful settlement would require.

The third idea is that unverifiability of military technology can prevent the peaceful settlement of a new territorial dispute and also can cause an existing peaceful settlement of an old territorial dispute to break down, with armed conflict resulting. This idea is related to the analysis of Dagobert Brito and Michael Intriligator (1985) and James Fearon (1995) in which war results from asymmetric information that produces inconsistently optimistic expectations about the probabilities of success in armed conflict. The present paper adds the observation that information about the relative effectiveness of spending on arms derived from the experience of armed conflict can provide the basis for a future peaceful settlement.

\footnotetext{
${ }^{3}$ In Garfinkel's model states contest control over capital stocks that are endogenously determined. In the present paper the analysis is simplified by taking the value of controlling the contested territory to be exogenous. In related work on territorial conflict Ronald Findlay (1996) and Herschel Grossman and Juan Mendoza (2002) analyze the expansion of empires, but these analyses do not consider the possibility of agreements to limit arms.
} 


\section{A Model of Territorial Conflict}

Consider two sovereign states, denoted State 1 and State 2, each of which wants to control a contested territory. Either these two states negotiate a peaceful settlement of their territorial dispute or they engage in an armed conflict for control of the contested territory.

Although, as mentioned, the analysis of how these states resolve their territorial dispute is broadly relevant, for tractability the analysis abstracts from several complications. Specifically, the analysis utilizes throughout the following simplifying assumptions:

- The dispute does not concern either the survival of the two states or control of their heartlands and other uncontested domains. Hence, an armed conflict for control of the contested territory would not call for a total mobilization of resources and would not face either state with a binding constraint on its ability to mobilize resources.

- Interaction between the two states, through either conflict or negotiation, determines control of the contested territory without reference to the preferences of the inhabitants of the contested territory. ${ }^{4}$

- The states act in this dispute as if they are unitary agents. Their internal politics do not bear on this dispute. ${ }^{5}$

- The state that wins an armed conflict for control of the contested territory in the current period would gain control of the entire contested territory, but only for the current period. Hence, the states potentially face this territorial dispute repeatedly. ${ }^{6}$

\footnotetext{
${ }^{4}$ Alberto Alesina and Enrico Spolaore (1997, 2003) develop a complementary analysis in which the preferences of the inhabitants of regions play a role in determining the incorporation of regions into sovereign states and, thereby, help to determine the boundaries of sovereign states.

${ }^{5}$ Examples of recent literature on the relation between politics and war include Garfinkel (1994) and Gregory Hess and Athanasios Orphanides (1995, 2001).

${ }^{6}$ If, alternatively, the winner of an armed conflict would gain permanent control of the contested territory, then the prospective costs of future armed conflicts could not serve to make an agreement to settle the dispute
} 
- Arms include a combination of manpower and items of military hardware that, whether or not they are used up in an armed conflict, either depreciate or become obsolete within a few years. A period, accordingly, is the number of years necessary to prepare for a new armed conflict either by arming or rearming.

- An armed conflict for control of the contested territory would not cause significant collateral damage. ${ }^{7}$

- The value for either state of controlling the fraction $k$ of the contested territory in the current period would be $k$ times that the value of controlling the entire territory. ${ }^{8}$

Let $\alpha$ denote the value for either state of controlling the entire contested territory in the current period, and let $r_{1}$ and $r_{2}$ denote the amounts of resources that in the event of armed conflict State 1 and State 2 would mobilize in the current period - that is, the amounts that the states would spend on arms. Assume that each state would choose its spending on arms to maximize its expected value of armed conflict, taking as given the other state's spending on arms. ${ }^{9}$ Abstracting from collateral damage, the sum of $r_{1}$ and $r_{2}$ peacefully credible. Fearon (1995) analyses the problem of the credibility of peaceful settlements in a model in which adversaries do not interact repeatedly.

${ }^{7}$ An expectation of collateral damage, which with some effort could be incorporated into the analysis, would add to the expected cost of armed conflict and would enhance the possibility of a peaceful settlement.

${ }^{8} \mathrm{In}$ this formulation the marginal value of controlling more of the contested territory is constant. We can readily generalize the analysis to allow for this marginal value either to be decreasing, in which case the possibility of a peaceful settlement would be enhanced, or to be increasing, in which case the possibility of a peaceful settlement would be diminished.

${ }^{9} \mathrm{An}$ alternative would be to assume that one state is a Stackelberg leader, who can make an irreversible choice of its spending on arms before the other state makes its choice. The analysis in Grossman and Minseong Kim (1995) and in Dmitriy Gershenson and Grossman (2000) suggest conditions under which a Stackelberg leader would choose to spend enough on arms to cause the other state to give up its claim to the contested territory. 
would represent the cost of an armed conflict.

Let $p_{1}$ and $p_{2}$, where $p_{1}+p_{2}=1$, denote the probabilities that State 1 or State 2 would win an armed conflict. Given that both $r_{1}$ and $r_{2}$ are positive, assume, as in a standard contest-success function, that $p_{1}$ and $p_{2}$ depend on $r_{1}$ and $r_{2}$ according to (1) $\quad p_{1}=\frac{1}{1+r_{2} / \theta r_{1}} \quad$ and $\quad p_{2}=\frac{1}{1+\theta r_{1} / r_{2}}, \quad$ where $\theta \equiv \frac{\phi}{1-\phi}, \quad 0<\phi<1$.

The parameter $\phi$ in equations (1) measures the effectiveness of spending on arms by State 1 relative to the effectiveness of spending on arms by State 2. A value of $\phi$ larger than one half, or, equivalently, a value of $\theta$ larger than one, would mean that the State 1 has an advantage in armed conflict, and vice versa. Assume for now that the value of $\phi$ is common knowledge and that the states behave as if $\phi$ is a constant. ${ }^{10}$

Let $N_{1}$ and $N_{2}$ denote the expected values of armed conflict for State 1 and State 2, where, given the probabilities of winning the armed conflict, the value of controlling the entire contested territory in the current period, and the amounts spent on arms, we have

$$
N_{1}=p_{1} \alpha-r_{1} \quad \text { and } \quad N_{2}=p_{2} \alpha-r_{2}
$$

From equations (1) and (2) interior solutions to the problem for each state of choosing spending on arms to maximize the expected value of armed conflict would satisfy the firstorder conditions,

$$
\frac{d N_{1}}{d r_{1}}=\alpha \frac{\partial p_{1}}{\partial r_{1}}-1=0 \quad \text { and } \quad \frac{d N_{2}}{d r_{2}}=\alpha \frac{\partial p_{2}}{\partial r_{2}}-1=0 .
$$

These first-order conditions imply the following reaction functions:

$$
r_{1}=\sqrt{\alpha r_{2} / \theta}-r_{2} / \theta \quad \text { and } \quad r_{2}=\sqrt{\alpha \theta r_{1}}-\theta r_{1}
$$

\footnotetext{
${ }^{10}$ Because equations (1) are not linear in $\phi$, this assumption is not innocuous. If the states recognized $\phi$ to be a stochastic variable, then their behavior would depend not only on the expected value of $\phi$, but also on higher moments of the stochastic process generating $\phi$.
} 
Solving equations (3) for $r_{1}$ and $r_{2}$ in terms of $\alpha$ and $\phi$, we obtain

$$
r_{1}=r_{2}=\alpha \phi(1-\phi)
$$

Given that $r_{1}$ and $r_{2}$ would be equal, equations (1) imply that the probabilities associated with each state winning control of the territory would be $p_{1}=\phi$ and $p_{2}=1-\phi$. By substituting equations (1) and (4) into equations (2), we obtain solutions for $N_{1}$ and $N_{2}$ in terms of $\alpha$ and $\phi$,

$$
N_{1}=\alpha \phi^{2} \quad \text { and } \quad N_{2}=\alpha(1-\phi)^{2} .
$$

If $\phi$ were equal to one half, and, equivalently, $\theta$ were equal to one, in which case neither State 1 nor State 2 would have an advantage in armed conflict, then according to equations (4) and (5) $r_{1}$ and $r_{2}$ and $N_{1}$ and $N_{2}$ each would equal $\alpha / 4$. In this case armed conflict would dissipate exactly one-half of the value of the contested territory.

\section{An Unfortified Border?}

Now, suppose that these states, seeking an alternative to armed conflict, were to enter into negotiations to settle their border dispute and were to consider an agreement with two provisions:

- First, divide control of the contested territory with State 1 and State 2 getting control over the fractions $k_{1}$ and $k_{2}$ respectively, where $k_{1}+k_{2}=1$.

- Second, promise not to acquire arms intended for use, either defensively or offensively, in armed conflict for control of the contested territory.

Under this agreement the border would be unfortified, and the territorial dispute would be resolved peacefully.

Would such an agreement be viable? Specifically, if one state does not arm, could the other state credibly promise not to use armed force to attempt to gain control of the entire 
contested territory? To answer this question, assume that either state would break its promise not to use armed force if and only if, taking into account both current consequences and expected future consequences, the expected value of breaking its promise would be larger than the expected value of keeping its promise. ${ }^{11}$

To determine the expected value of keeping a promise, assume that, as long as both states keep their promises, they can make credible promises in the future. To determine the expected value of breaking a promise, assume that, if one state does not arm, then the other state could seize the entire contested territory in the current period by surreptitiously spending a negligible amount on arms. But, assume further that, as long as the parameters on which the agreement not to arm is based have not changed, if either state were to break its promise, then future peaceful settlements would be precluded. In that event, starting in the next period, the states would have to bear the costs of periodical armed conflict permanently. $^{12}$

These assumptions imply that the promises of both states not to arm would be credible if and only if $k_{1}$ and $k_{2}$ satisfy the following credibility conditions:

$$
\frac{k_{1} \alpha}{1-\rho \gamma} \geq \alpha+\frac{\rho \gamma}{1-\rho \gamma} N_{1} \quad \text { and } \quad \frac{k_{2} \alpha}{1-\rho \gamma} \geq \alpha+\frac{\rho \gamma}{1-\rho \gamma} N_{2}
$$

where the positive parameter $\gamma$ is a growth factor, and where the parameter $\rho, \rho<1 / \gamma$, is

\footnotetext{
${ }^{11}$ This assumption abstracts from the possibility that states can bond themselves to keep their promises by offering collateral or other hostages. A large literature deals with the question of whether or not political agents can bond themselves. See, for example, Jeremy Bulow and Kenneth Rogoff (1989).

${ }^{12}$ The analysis can easily be generalized to allow for a possibility that armed conflict would not be permanent. For example, we could assume that the value of controlling the contested territory is a random variable that evolves over time according to the following simple stochastic process: Given that this value is positive in the current period, with some probability this value will be will positive in the next period and with the complementary probability this value will be zero in the next period and in all subsequent periods. In this formulation model the probability that the territory will remain valuable would be a component of the discount factor used in valuing expected future control of the territory. Also, armed conflict would continue only for as long as control of the territory remained valuable.
} 
a discount factor. In this formulation the value of controlling the entire contested territory grows at a constant rate of $\gamma-1$ per period.

The left sides of conditions (6) are the expected value to each state of keeping its promise not to arm, given that the other state keeps its promise and that both states will keep their promises in the future. As long as both states keep their promises, each state would receive now and in the future the value of its agreed fraction of the territory, adjusted for the growth factor and the discount factor.

The right sides of conditions (6) are the expected value to each state of breaking its promise. By breaking its promise, a state at a negligible cost would receive in the current period the value of controlling the entire territory, but in the future it would obtain only its expected value from armed conflict, either $N_{1}$ or $N_{2}$, adjusted for the growth factor and the discount factor. The assumption that the states behave as if $\phi$ is a constant implies that they behave as if $N_{1}$ and $N_{2}$ are constants.

Setting $k_{2}$ equal to $1-k_{1}$ in conditions (6), and substituting from equations (5) for $N_{1}$ and $N_{2}$, we find that conditions (6) are satisfied if and only if $k_{1}$ satisfies

$$
\rho \gamma\left[1-(1-\phi)^{2}\right] \geq k_{1} \geq 1-\rho \gamma\left(1-\phi^{2}\right) .
$$

There exist one or more values of $k_{1}$ that can satisfy conditions (7) if and only if the left side of conditions (7) is equal to or larger than the right side of conditions (7). This weak inequality in turn obtains if and only if the parameters, $\phi, \rho$, and $\gamma$, satisfy

$$
\rho \gamma \geq \frac{1}{1+2 \phi(1-\phi)} .
$$

Condition (8) implies that there exist one or more values of $k_{1}$ that can satisfy conditions (7) if and only if the product of $\rho$ and $\gamma$ is sufficiently large and $\phi$ is sufficiently close to one half. Figure 1 depicts the combinations of $\rho \gamma$ and $\phi$, as indicated by the region labeled "unfortified border", that satisfy condition (8). ${ }^{13}$ Condition (8) and Figure 1 imply

\footnotetext{
${ }^{13}$ Condition (8) does not involve $\alpha$ because both sides of the conditions (6) are proportionate to $\alpha$.
} 


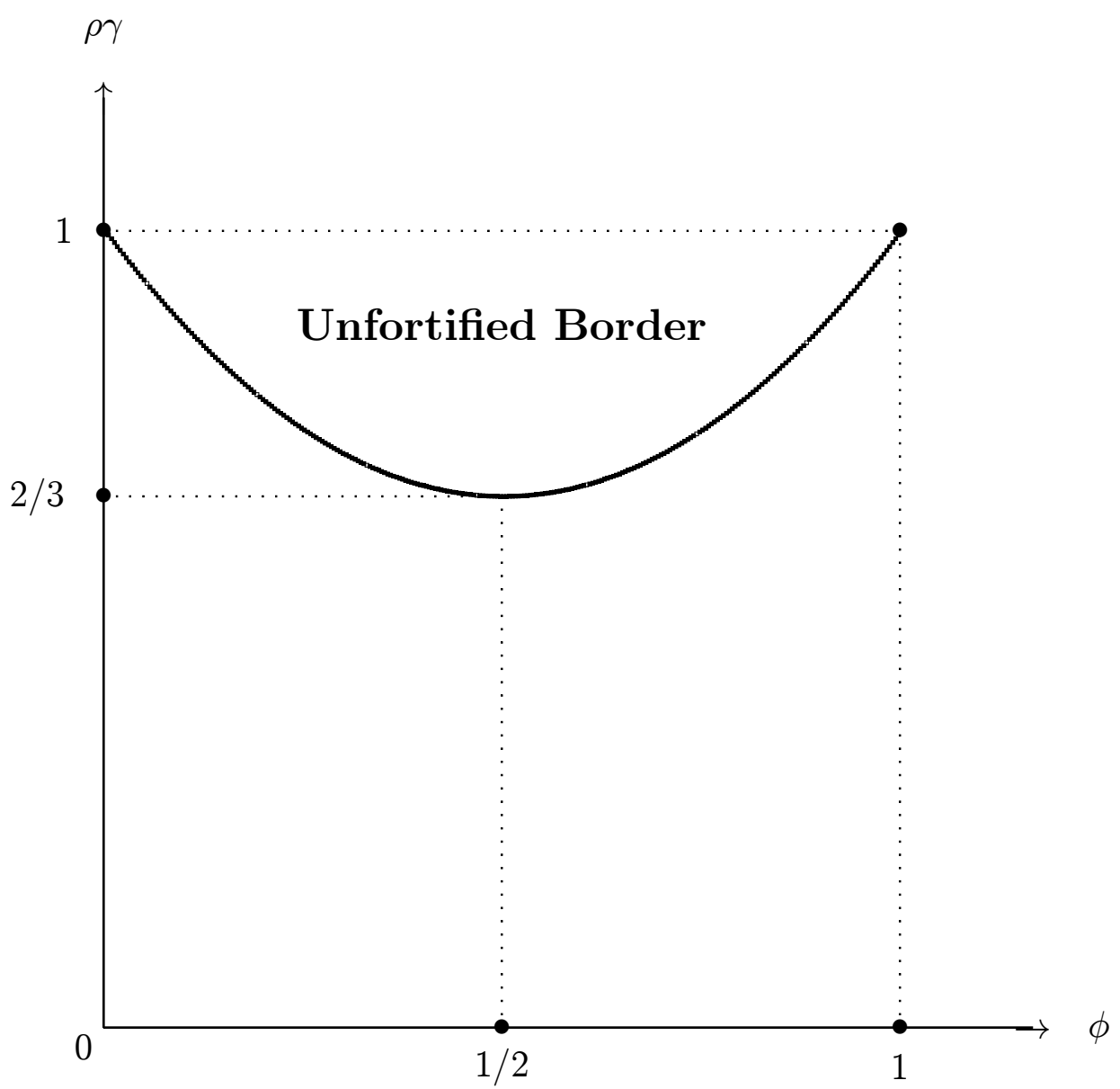

Figure 1: The Possibility of an Unfortified Border 
the following result:

\section{Result 1: If the product of the discount factor and the growth factor is sufficiently large, then states can negotiate a credible agreement to divide control of a contested territory and not to acquire arms intended for use in armed conflict for control of the contested territory. The smallest critical value of the product of the discount factor and the growth factor obtains for states for whom the effectiveness of spending on arms is equal.}

The importance of a large value of $\rho \gamma$ exemplifies the "folk theorem" from the standard theory of repeated interactions between adversaries. The larger is $\rho \gamma$ the more valuable it is to have an viable agreement to avoid future armed conflict. Hence, with a sufficiently large value of $\rho \gamma$ the prospect of armed conflict in the future would mitigate the temptation to break the agreement by using armed force to seize control of the entire contested territory for the current period. ${ }^{14}$

The importance of $\phi$ being close to one half is a more novel result. For values of $\phi$ much larger than one half, State 1 would have little to fear from future armed conflict, whereas for values of $\phi$ much smaller than one half, State 2 would have little to fear from future armed conflict. Thus, values of $\phi$ that are either much larger or much smaller than one half weaken for one state or the other the effect of the prospect of future armed conflict in deterring armed conflict in the current period.

\footnotetext{
${ }^{14}$ In this model, as in the standard theory of repeated interactions between adversaries, either a larger growth factor or a larger discount factor facilitates a peaceful settlement. Alternatively, if the state that wins an initial armed conflict were to gain control of the contested territory permanently, then the states would not interact repeatedly, and, interestingly, either a larger growth factor or a larger discount factor would intensify conflict. Examples of models that exhibit this property include Robert Powell (1993), Stergios Skaperdas and Constantinos Syropoulos (1996), Grossman (1999), and Garfinkel and Skaperdas (2000).
} 
This theory suggests that Result 1 applies to the United States and Canada as well as to those European states, France and Germany being prime examples, that after a long history of armed territorial conflicts have now been able to dispense with border fortifications. Of course, in these cases factors from which the analysis has abstracted probably have helped to make agreements not to fortify borders credible. For example, these states can expect that armed conflict would cause significant collateral damage. Also, these states can fear that breaking a promise not to use armed force to seize a contested territory would preclude future peaceful settlements not only of this territorial dispute but of other potential disputes.

In a credible agreement not to fortify the border, how do the states divide the contested territory? If the combination of $\rho \gamma$ and $\phi$ satisfies condition (8) as an equality, then a unique value of $k_{1}$ would satisfy conditions (7). Alternatively, if $\rho \gamma$ and $\phi$ satisfy condition (8) as an inequality, then a range of values of $k_{1}$ would satisfy conditions (7). In addition conditions (7) imply that both the minimum and maximum possible values of $k_{1}$ in this range are increasing functions of $\phi$. Thus, conditions (7) imply the following result:

\section{Result 2: Under a credible agreement not to acquire arms intended for use in armed conflict for control of a contested territory a state can control a larger share of the contested territory the larger would be the relative effectiveness of its spending on arms.}

Figure 2 illustrates conditions (7). This figure depicts how the range of values for $k_{1}$ that satisfy condition (7) depends on $\rho \gamma$ and $\phi$. As we have seen, conditions (7) can be satisfied only if $\rho \gamma$ is at least as large as two thirds. In addition, if $\rho \gamma$ equals two thirds, then only the combination of $\phi$ equal to one half and $k_{1}$ and $k_{2}$ equal to one half would satisfy conditions (7). But, if $\rho \gamma$ is larger than two-thirds, then all combinations of $\phi$ and $k_{1}$ in a set such as the set enclosed by the broken loci would satisfy conditions (7). In the limit as $\rho \gamma$ approaches one, all combinations of $\phi$ and $k_{1}$ in the set enclosed by the solid loci would satisfy conditions (7). 


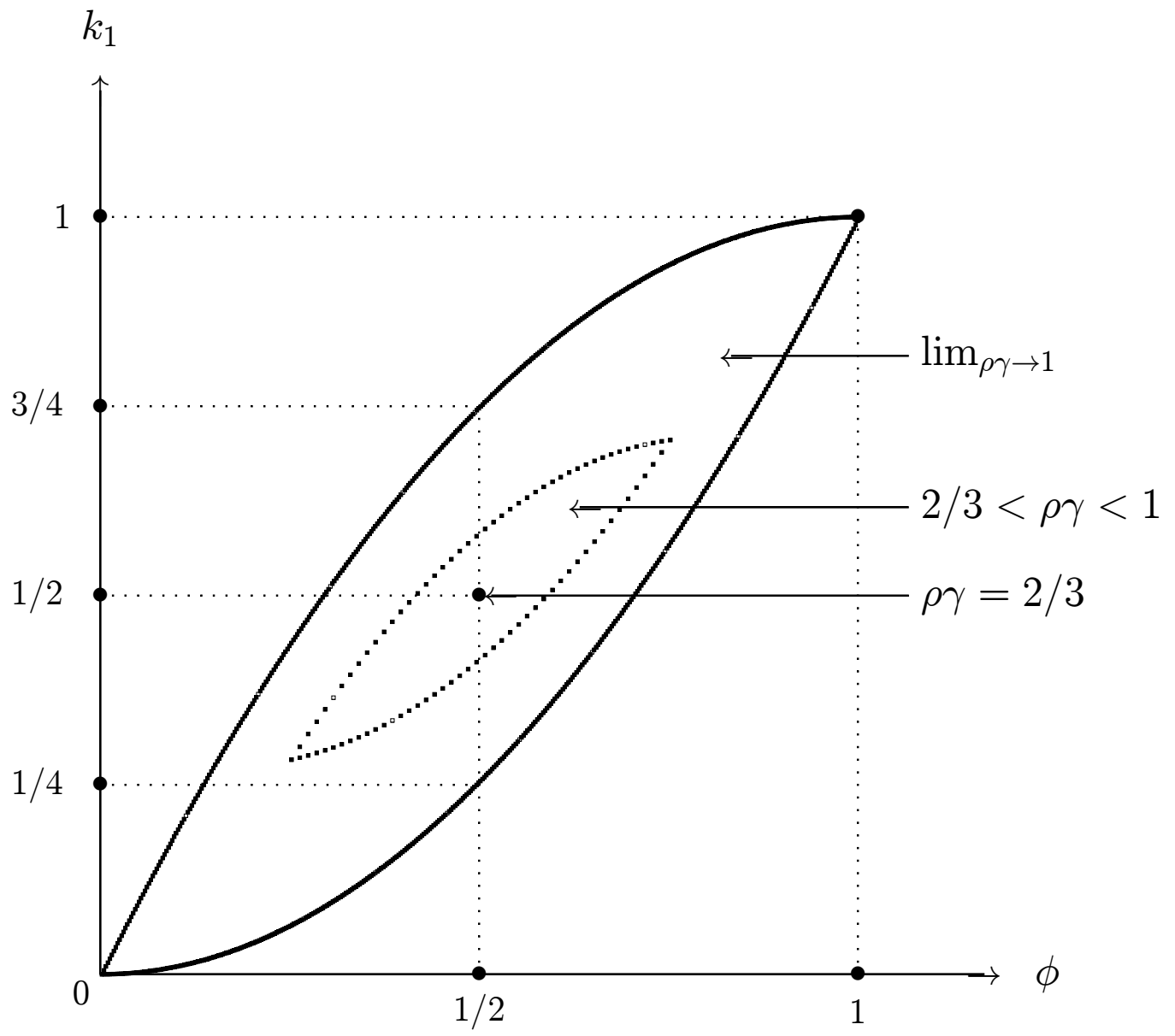

Figure 2: Division of Territory with an Unfortified Border 


\section{A Fortified but Peaceful Border?}

Suppose that the parameters, $\phi$ and $\rho \gamma$, do not satisfy condition (8). As a result the states cannot make a credible agreement to divide the contested territory and to leave the border unfortified.

Now, suppose that the states were to consider an alternative agreement with the following three provisions:

- First, as before, divide control of the contested territory with State 1 and State 2 getting the fractions $k_{1}$ and $k_{2}$, where $k_{1}+k_{2}=1$.

- Second, spend positive amounts, denoted by $r_{1}^{*}$ and $r_{2}^{*}$, on fortifying the resulting border.

- Third, promise not to use force to attempt to gain control of the entire contested territory.

If the sum of $r_{1}^{*}$ and $r_{2}^{*}$ were smaller than twice $\alpha \phi(1-\phi)$, which is the amount that the two states together would spend on arms in the event of armed conflict, then, although the border would be fortified, this alternative agreement would resolve the dispute over control of the contested territory peacefully and with less cost than an armed territorial conflict.

Would this alternative agreement be credible? To answer this question, assume that either state would break its promise not to use force to attempt to gain control of the entire contested territory if and only if the expected value of breaking its promise would be larger than the expected value of keeping its promise. To determine the expected value of keeping a promise under this alternative agreement, assume as before that, as long as both states keep their promises, they can make credible promises in the future. To determine the expected value of breaking a promise under this alternative agreement, assume that, were it to break its promise, State 1 would spend on arms an amount, denoted by $\tilde{r}_{1}$, that would maximize its expected value of armed conflict, taking $r_{2}^{*}$ as given, and similarly for State 2 . 
Using equations (3) we obtain the following solutions for $\tilde{r}_{1}$ and $\tilde{r}_{2}$ :

$$
\tilde{r}_{1}=\sqrt{\alpha r_{2}^{*} / \theta}-r_{2}^{*} / \theta \quad \text { and } \quad \tilde{r}_{2}=\sqrt{\alpha \theta r_{1}^{*}}-\theta r_{1}^{*} .
$$

Substituting equations (9) into equations (1), we find that, if either State 1 or State 2 were to break its promise, then its probability of winning control of the territory, denoted by either $\tilde{p}_{1}$ or $\tilde{p}_{2}$, would be

$$
\tilde{p}_{1}=1-\sqrt{r_{2}^{*} / \alpha \theta} \quad \text { and } \quad \tilde{p}_{2}=1-\sqrt{\theta r_{1}^{*} / \alpha} .
$$

Also, assume that, as before, if either state were to break its promise, then, starting in the next period, the states would have to bear the costs of periodical armed territorial conflict permanently. Under these assumptions the promises of both states would be credible if and only if $k_{1}$ and $r_{1}^{*}$ and $k_{2}$ and $r_{2}^{*}$ satisfy the following credibility conditions:

$$
\begin{aligned}
& \frac{k_{1} \alpha-r_{1}^{*}}{1-\rho \gamma} \geq \tilde{p}_{1} \alpha-\tilde{r}_{1}+\frac{\rho \gamma}{1-\rho \gamma} N_{1} \quad \text { and } \\
& \frac{k_{2} \alpha-r_{2}^{*}}{1-\rho \gamma} \geq \tilde{p}_{2} \alpha-\tilde{r}_{2}+\frac{\rho \gamma}{1-\rho \gamma} N_{2} .
\end{aligned}
$$

The left sides of conditions (11) are the expected value to each state of keeping its promise, given that the other state keeps its promise and that both states will keep their promises in the future. The right sides of conditions (11) are the expected value to each state of breaking its promise. If a state were to break its promise, then in the current period it would incur the cost of the amount that it would choose to spend on arms, either $\tilde{r}_{1}$ or $\tilde{r}_{2}$, and with probability of either $\tilde{p}_{1}$ or $\tilde{p}_{2}$ it would receive the benefit, $\alpha$, from controlling the entire territory. In future periods it would obtain its expected value from armed conflict.

Conditions (11) generalize conditions (6) to allow for positive values of $r_{1}^{*}$ and $r_{2}^{*}$. Comparing conditions (11) with conditions (6) we see that the expense of fortifying the border, as represented by positive values of $r_{1}^{*}$ and $r_{2}^{*}$, makes the expected value to each state of keeping its promise smaller, but that with the border fortified the expected value 
to each state of breaking its promise also is smaller. As we will now see, because the latter effect dominates, conditions (11) can be satisfied, with large enough values of $r_{1}^{*}$ and $r_{2}^{*}$, even though condition (8) is not satisfied.

Because $k_{2}$ equals $1-k_{1}$, conditions (11) are equivalent to

$$
\begin{gathered}
A \geq k_{1} \geq B, \\
\text { where } \quad A \equiv 1-(1-\rho \gamma) \tilde{p}_{2}-\rho \gamma \frac{N_{2}}{\alpha}+(1-\rho \gamma) \frac{\tilde{r}_{2}}{\alpha}-\frac{r_{2}^{*}}{\alpha} \\
\text { and } \quad B \equiv(1-\rho \gamma) \tilde{p}_{1}+\rho \gamma \frac{N_{1}}{\alpha}-(1-\rho \gamma) \frac{\tilde{r}_{1}}{\alpha}+\frac{r_{1}^{*}}{\alpha} .
\end{gathered}
$$

Accordingly, in a credible agreement $r_{1}^{*}$ and $r_{2}^{*}$ must be such that $A$ is equal to or larger than $B$. Moreover, an agreement that minimizes the sum, $r_{1}^{*}+r_{2}^{*}$, subject to $A$ being equal to or larger than $B$, would minimize the cost of resolving the territorial dispute peacefully. Assuming that the savings from minimizing spending on fortifying the border are transferable, both states would want to make such an agreement.

Substituting equations (9) for $\tilde{r}_{1}$ and $\tilde{r}_{2}$, equations (10) for $\tilde{p}_{1}$ and $\tilde{p}_{2}$, and equations (5) for $N_{1}$ and $N_{2}$, into the expressions for $A$ and $B$, we obtain

$$
\begin{aligned}
& A=\rho \gamma\left[1-(1-\phi)^{2}\right]+2(1-\rho \gamma) \sqrt{\frac{\theta r_{1}^{*}}{\alpha}}-(1-\rho \gamma) \frac{\theta r_{1}^{*}}{\alpha}-\frac{r_{2}^{*}}{\alpha} \quad \text { and } \\
& B=1-\rho \gamma\left(1-\phi^{2}\right)-2(1-\rho \gamma) \sqrt{\frac{r_{2}^{*}}{\alpha \theta}}+(1-\rho \gamma) \frac{r_{2}^{*}}{\alpha \theta}+\frac{r_{1}^{*}}{\alpha} .
\end{aligned}
$$

The combination of $r_{1}^{*}$ and $r_{2}^{*}$ that minimizes the sum, $r_{1}^{*}+r_{2}^{*}$, subject to $A-B \geq 0$, would satisfy the first-order conditions,

$$
\frac{d(A-B)}{d r_{1}^{*}}=\frac{d(A-B)}{d r_{2}^{*}} \geq 0 \quad \text { and } \quad A-B=0,
$$

where, from equations (13), we have

$$
\frac{d(A-B)}{d r_{1}^{*}}=(1-\rho \gamma)\left(\sqrt{\frac{\theta}{\alpha r_{1}^{*}}}-\frac{\theta}{\alpha}\right)-\frac{1}{\alpha} \quad \text { and }
$$




$$
\frac{d(A-B)}{d r_{2}^{*}}=(1-\rho \gamma)\left(\sqrt{\frac{1}{\theta \alpha r_{2}^{*}}}-\frac{1}{\theta \alpha}\right)-\frac{1}{\alpha} .
$$

The concavity of the relation between the difference, $A-B$, and $r_{1}^{*}$ and $r_{2}^{*}$ insures that the combination of $r_{1}^{*}$ and $r_{2}^{*}$ that satisfies these first-order conditions also satisfies the requisite second-order conditions.

To explore the implications of conditions (14), begin by assuming that $\phi$ equals one half, and, equivalently, that $\theta$ equals one. Under this assumption neither State 1 nor State 2 has an advantage in armed conflict. With $\phi$ equal to one half, an analytical solution of conditions (14) reveals that a credible agreement to resolve the territorial dispute peacefully and at minimum cost would entail

$$
r_{1}^{*}=r_{2}^{*}=\left\{\begin{array}{cl}
\frac{\alpha}{4}\left(\frac{1-3 \rho \gamma / 2}{1-\rho \gamma / 2}\right)^{2} & \text { for } \quad 0 \leq \rho \gamma<\frac{2}{3} \\
0 & \text { for } \quad \rho \gamma \geq \frac{2}{3} .
\end{array}\right.
$$

According to equations (15), with $\phi$ equal to one half, for values of $\rho \gamma$ larger than $2 / 3$ the minimum values of $r_{1}^{*}$ and $r_{2}^{*}$ are zero. This result accords with condition (8). At the other extreme, if $\rho \gamma$ were equal to zero, then the values of $r_{1}^{*}$ and $r_{2}^{*}$ that minimize $r_{1}^{*}+r_{2}^{*}$ would equal $\alpha \phi(1-\phi)$, which is the amount that each state would spend on arms in the absence of a negotiated settlement. For values of $\rho \gamma$ that are positive but smaller than $2 / 3, r_{1}^{*}$ and $r_{2}^{*}$ are equal and inversely related to $\rho \gamma$ and, hence, are positive but smaller than $\alpha \phi(1-\phi)$. For example, with $\phi$ equal to one half, $2 \alpha \phi(1-\phi)$ equals $\alpha / 2$, whereas with $\rho \gamma$ equal to $1 / 4$ the minimized value of $r_{1}^{*}+r_{2}^{*}$ would be $\alpha / 4$, and with $\rho \gamma$ equal to $1 / 2$ the minimized value of $r_{1}^{*}+r_{2}^{*}$ would be $\alpha / 18$.

Figure 3 illustrates equations (15). Equations (15) and Figure 3 imply the following result:

Result 3: Even if an agreement to divide a contested territory and to leave the resulting border unfortified would not be credible, if the 


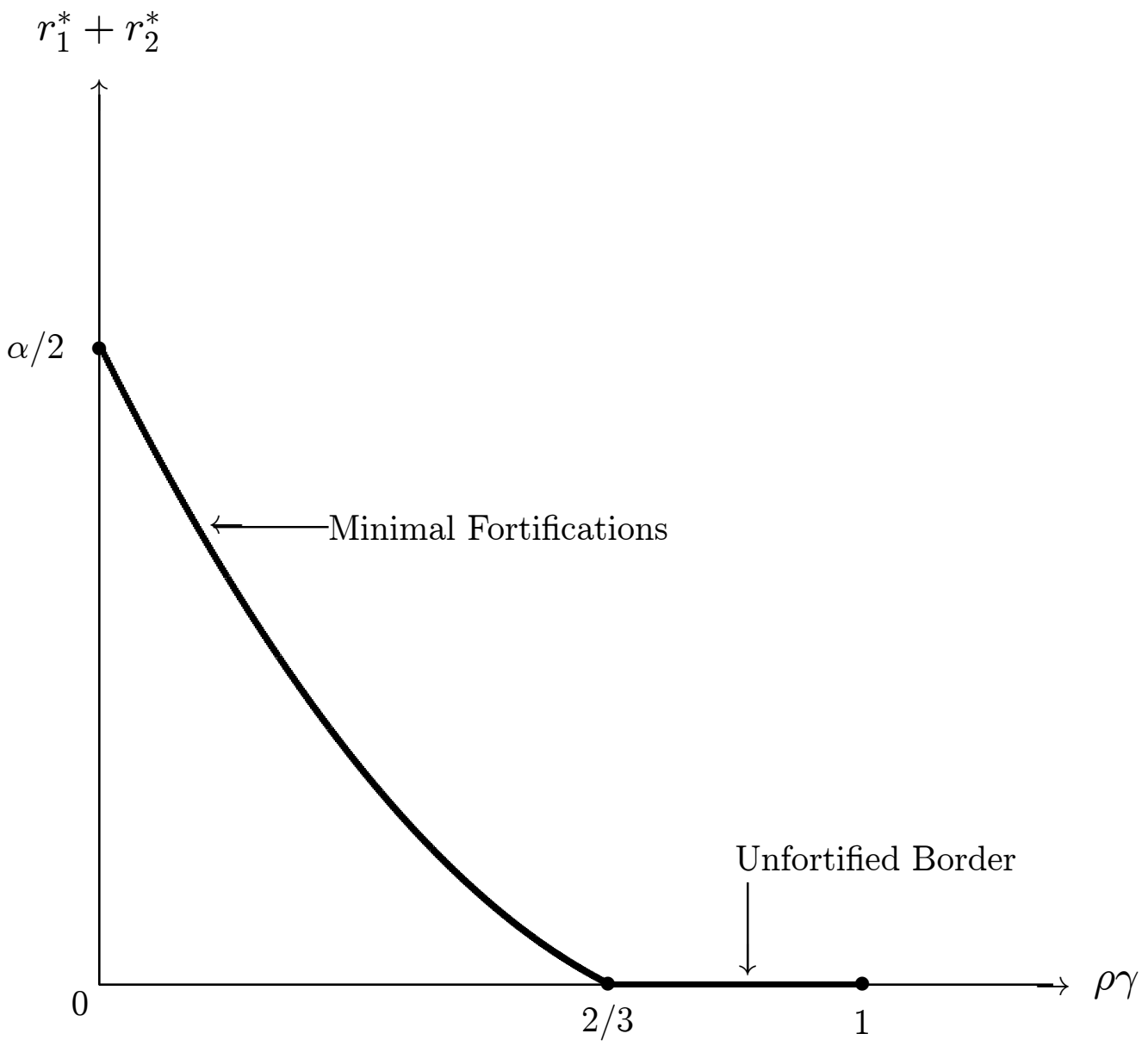

Figure 3: A Fortified but Peaceful Border 


\section{product of the discount factor and the growth factor is positive, then}

states can negotiate a credible agreement to divide the contested territory and, with the resulting border fortified, to resolve the territorial dispute peacefully and at a smaller cost than the cost of armed conflict.

Simulated solutions of conditions (14) reveal that this result generalizes for values of $\phi$ that are either larger or smaller than one half. Specifically, for values of $\phi$ not equal to one half, although the values of $r_{1}^{*}$ and $r_{2}^{*}$ that minimize $r_{1}^{*}+r_{2}^{*}$ would not be equal, the minimized sum $r_{1}^{*}+r_{2}^{*}$ would be smaller than $2 \alpha \phi(1-\phi)$. For example, with $\phi$ equal to one third, $2 \alpha \phi(1-\phi)$ equals $4 \alpha / 9$, whereas with $\rho \gamma$ equal to $1 / 4$ the minimized value of $r_{1}^{*}+r_{2}^{*}$ would be about $\alpha / 4$, and with $\rho \gamma$ equal to $1 / 2$ the minimized value of $r_{1}^{*}+r_{2}^{*}$ would be about $\alpha / 16$.

In deriving Result 3 we have not had to take account of destruction and other forms of collateral damage from armed conflict. As noted above, the expectation of collateral damage would add to the expected cost of armed conflict and, accordingly, would decrease the amount of spending on fortifications required for the credibility of an agreement to resolve a territorial dispute peacefully.

In a credible agreement to fortify the border, but to resolve the territorial dispute peacefully, how do the states divide the contested territory? Given that $r_{1}^{*}$ and $r_{2}^{*}$ satisfy the first-order conditions (14), which include $A-B=0$, conditions (11) and (12) are satisfied as equalities. Accordingly, $k_{1}$ and $k_{2}$ are uniquely determined. Specifically, if $\phi$ equals one half, in which case equations (15) determine $r_{1}^{*}$ and $r_{2}^{*}$, then conditions (12) imply that $k_{1}$ equals one-half. In addition, using simulated solutions of conditions (14) we find that for values of $\phi$ that are smaller than one half conditions (12) imply that $k_{1}$ is slightly smaller than $\phi$, and that $k_{1}$ also depends on $\rho \gamma$. For example, with $\phi$ equal to $1 / 4$ and $\rho \gamma$ equal to $1 / 2, \quad k_{1}$ equals approximately 0.23 , whereas with $\phi$ equal to $1 / 4$ and $\rho \gamma$ equal to $1 / 4, \quad k_{1}$ equals approximately 0.20 . 
In sum, we have the following result:

\begin{abstract}
Result 4: If neither state has an advantage in armed conflict, then a credible negotiated agreement that resolves a territorial dispute peacefully and minimizes the amounts spent on arms gives each state control over one-half of the contested territory. Alternatively, if one of the states has an advantage in armed conflict, then such a credible agreement would give that state control of a larger fraction of the contested territory that approximately accords with its advantage in armed conflict.
\end{abstract}

\title{
Armed Conflict
}

Condition (8) is necessary, but not sufficient, for states to reach a credible agreement to divide a contested territory and not to fortify the border. In addition to condition (8) being satisfied, for the possibility of such an agreement to be realized, the states have to recognize this possibility. In addition, they have to identify at least one value of $k_{1}$ in the range of values that would satisfy conditions (6) and (7), and they have to agree on a value of $k_{1}$ in that range. ${ }^{15}$

In addition, just as condition (8) is necessary, but not sufficient, for an unfortified border, the possibility of an agreement that satisfies conditions (11) is necessary, but not sufficient, for states to divide a contested territory and to maintain a fortified but peaceful border. For the possibility of a fortified but peaceful border to be realized, the states have to recognize this possibility. In addition, they have to identify at least one set of values of $r_{1}^{*}$ and $r_{2}^{*}$ and $k_{1}$ and $k_{2}$ in the range of values that would satisfy conditions (11), and they have to agree on a set of values of $r_{1}^{*}$ and $r_{2}^{*}$ and $k_{1}$ and $k_{2}$ in that range.

\footnotetext{
${ }^{15}$ Alberto Alesina and Allan Drazen (1991) show how with incomplete information bargaining over the gains from a potential Pareto improvement can become stalemated in "a war of attrition" that delays the realization of the Pareto improvement.
} 
Historical experience suggests that sovereign states are commonly able to overcome these obstacles and to reach agreements to settle territorial disputes peacefully, sometimes with borders fortified and sometimes with borders being unfortified. Even so, armed territorial conflict has not been a rare event. Some armed conflicts have involved newly arisen territorial disputes, as in the conflicts between Britain and France and between Spain and Portugal for control over territories in the New World. Other armed conflicts have involved the breakdown of existing agreements to settle old territorial disputes peacefully, as in the case of the Mexican-American War.

How can our model be amended to allow for armed conflict? One possibility is to relax the assumption that the effectiveness of spending on arms by State 1 relative to spending on arms by State 2, as measured by the parameter $\phi$, is common knowledge.

Consider a newly arisen territorial dispute. Because the larger is $\phi$ the larger is the share of the contested territory that State 1 could control in a negotiated settlement, State 1 would be inclined to claim that $\phi$ is large, whereas State 2 would be inclined to claim that $\phi$ is small. But, suppose that, having never engaged in armed conflict with each other, neither state can readily verify the claim of the other state. Specifically, assume that states faced with a new territorial dispute can learn about the relative effectiveness of spending on arms only from the experience of armed conflict. This assumption implies that armed conflict can be a necessary prelude to a negotiated settlement of a newly arisen dispute. ${ }^{16}$

What about the breakdown of existing agreements to settle territorial disputes peacefully? Let us start with a situation in which from a previous experience of armed conflict both states know the value of $\phi$. Given the value of $\phi$ the two states have divided control of the contested territory and, with the border either unfortified or fortified, they also have made credible promises not to use force to attempt to gain control of the entire contested territory.

\footnotetext{
${ }^{16}$ If control of the territory could be more valuable for one of the states than for the other, then unverifiable claims about the value of controlling the territory would be another possible cause of armed conflict.
} 
Now suppose that State 1 realizes an innovation, involving, for example, an improvement in its weaponry or an improvement in its military tactics, that increases the relative effectiveness of its spending on arms. Suppose also that, as a result of this innovation, $\phi$ has increased so much that, given the previously agreed combination of $k_{1}$ and $k_{2}$ and $r_{1}^{*}$ and $r_{2}^{*}$, State 1 would break its promise not to use force to attempt to gain control of the entire contested territory. ${ }^{17}$

If State 2 could verify the increase in $\phi$, then, rather than facing armed conflict, State 2 would prefer to revise its agreement with State 1 in such a way that the credibility conditions for both states again would be satisfied. This revision presumably would involve an adjustment of the border to give State 1 a larger share of the contested territory. This revision also might involve changes in the amounts, if any, spent on fortifying the border.

In fact, it not easy for one state to verify an innovation that increases the effectiveness of spending on arms by the other state without seeing the consequences of this innovation. Accordingly, assume that State 1 can show State 2 that $\phi$ has increased only by breaking its promise not to use force to attempt to gain control of the entire contested territory. Importantly, however, because this action would show that one of the parameters on which the existing agreement was based has changed, breaking a promise in this case would not preclude peaceful settlements in the future.

Accordingly, an innovation that increases the relative effectiveness of spending on arms by either one state or the other can cause the breakdown of an existing agreement to resolve a territorial dispute peacefully, with a period of armed conflict resulting. The information about the relative effectiveness of spending on arms derived from the experience of armed

\footnotetext{
${ }^{17}$ The possibility of an innovation in $\phi$ is not consistent with the earlier simplifying assumption that the states behave as if $\phi$ is a constant. Also, conditions (11) do not allow for the possibility that a state would break an agreement that had previously been credible. On these points I ask the reader to permit me to employ the common contrivance of allowing an event to occur even though agents behaved as if they had attached zero probability to its occuring.
} 
conflict would provide the basis for a new negotiated settlement.

This analysis can account for the Mexican-American War. Apparently the Mexicans initially rejected American proposals to adjust the border because, having observed the recent poor performance of the American army in the Second Seminole War, the Mexicans underestimated the relative effectiveness of American spending on arms. The lessons learned from the Mexican-American War induced the Mexicans to cede a large fraction of the contested territory. These lessons also have prevented another armed conflict between Mexico and the United States. In contrast, the Americans and the British apparently had enough knowledge about the relative effectiveness of their spending on arms to be able to settle the dispute over the Oregon territory without an armed conflict.

\section{Summary}

This paper has suggested an explanation for why some borders between sovereign states are unfortified, why other borders are fortified but peaceful, and, importantly, why territorial disputes sometimes result in armed conflict. Initially the analysis assumed that the effectiveness of spending on arms by one state relative to another is fixed and is also common knowledge. Given these assumptions, we derived the following results.

1. If the product of the discount factor and the growth factor is sufficiently large, then states can negotiate a credible agreement to divide control of a contested territory and not to acquire arms intended for use in armed conflict for control of the contested territory. The smallest critical value the product of the discount factor and the growth factor obtains for states for whom the effectiveness of spending on arms is equal.

2. Under a credible agreement not to acquire arms intended for use in armed conflict for control of a contested territory a state can control a larger share of the contested territory the larger would be the relative effectiveness of its spending on arms.

3. Even if an agreement to divide a contested territory and to leave the resulting border 
unfortified would not be credible, if the product of the discount factor and the growth factor is positive, then states can negotiate a credible agreement to divide the contested territory and, with the resulting border fortified, to resolve the territorial dispute peacefully and at a smaller cost than the cost of armed conflict.

4. If neither state has an advantage in armed conflict, then a credible negotiated agreement that resolves a territorial dispute peacefully and minimizes the amounts spent on arms gives each state control over one-half of the contested territory. Alternatively, if one of the states has an advantage in armed conflict, then such a credible agreement would give that state control of a larger fraction of the contested territory that approximately accords with its advantage in armed conflict.

The analysis then considered the possibility that the effectiveness of spending on arms by one state relative to another is neither fixed nor necessarily common knowledge. Specifically, the analysis assumed that states faced with a new territorial dispute or faced with an innovation in the relative effectiveness of spending on arms can learn about the relative effectiveness of spending on arms only from the experience of armed conflict. Under this assumption armed conflict can be a necessary prelude to a negotiated settlement of a newly arisen territorial dispute. In addition, an innovation that increases the relative effectiveness of spending on arms by either one state or the other can cause the breakdown of an existing agreement to resolve a territorial dispute peacefully, with a period of armed conflict resulting. The information about the relative effectiveness of spending on arms derived from the experience of armed conflict would provide the basis for a new negotiated settlement. 


\section{References}

Alesina, Alberto, and Drazen, Allan. "Why are Stabilizations Delayed?" American Economic Review, 81(5), December 1991, 829-850.

Alesina, Alberto, and Spolaore, Enrico. "On the Number and Size of Nations", Quarterly Journal of Economics, 112(4), November 1997, 1027-1056.

Alesina, Alberto, and Spolaore, Enrico. The Size of Nations, MIT Press, 2003.

Brito, Dagobert and Intriligator, Michael. "Conflict, War, and Redistribution", American Political Science Review, 79, December 1985, 943-957.

Bulow, Jeremy and Rogoff, Kenneth. "A Constant Recontracting Model of Sovereign Debt", Journal of Political Economy, 97(1), February 1989, 155-178.

Fearon, James D. "Rationalist Explanations for War", International Organization, 49(3), Summer 1995, 379-414.

Findlay, Ronald. "Towards a Model of Territorial Expansion and the Limits of Empire", in Garfinkel, Michelle and Skaperdas, Stergios, (eds.) The Political Economy of Conflict and Appropriation, Cambridge University Press, 1996, 41-56.

Garfinkel, Michelle. "Arming as a Strategic Investment in a Cooperative Equilibrium", American Economic Review, 80(1), March 1990, 50-68.

Garfinkel, Michelle. "Domestic Politics and International Conflict", American Economic Review, 84(5), December 1994, 1294-1309.

Garfinkel, Michelle and Skaperdas, Stergios, "Conflict Without Misperceptions or Incomplete Information: How the Future Matters," Journal of Conflict Resolution, 44(6), December 2000, 793-807.

Gershenson, Dmitriy and Grossman, Herschel I. "Civil Conflict: Ended or Never Ending?" Journal of Conflict Resolution, 44(6), December 2000, 807-821.

Grossman, Herschel I. "Kleptocracy and Revolutions", Oxford Economic Papers, 51(2), April 1999, 267-283. 
Grossman, Herschel I. and Kim, Minseong. "Swords or Plowshares? A Theory of the Security of Claims to Property", Journal of Political Economy, 103(6), December 1995, $1275-1288$.

Grossman, Herschel I. and Mendoza, Juan. "The Economics of Empire Building", unpublished, September 2002.

Hess, Gregory and Orphanides, Athanasios. "War Politics: An Economic, Rational-Voter Framework", American Economic Review, 85(4), September 1995, 828-846.

Hess, Gregory and Orphanides, Athanasios. "War and Democracy", Journal of Political Economy, 109(4), August 2001, 776-810.

Miles, Edwin A. "'Fifty-four Forty or Fight' - An American Political Legend", The Mississippi Valley Historical Review, 44(2), September 1957, 291-309.

Pletcher, David M. The Diplomacy of Annexation: Texas, Oregon, and the Mexican War, University of Missouri Press, 1973.

Powell, Robert. "Guns, Butter, and Anarchy", American Political Science Review, 87(1), March 1993, 115-132.

Sperber, Hans. "Fifty-four Forty or Fight': Facts and Fictions", American Speech, 32(1), February 1957, 5-11.

Skaperdas, Stergios and Syropoulos, Constantinos. "Can the Shadow of the Future Harm Cooperation?" Journal of Economic Behavior and Organization, 29(3), May 1996, 355372. 